\title{
Geographic Information Systems: Tools for Displaying In-Library Use Data Lauren H. Mandel
}

In-library use data is crucial for modern libraries to understand the full spectrum of patron use, including patron self-service activities, circulation, and reference statistics. Rather than using tables and charts to display use data, a geographic information system (GIS) facilitates a more visually appealing graphical display of the data in the form of a map. GISs have been used by library and information science (LIS) researchers and practitioners to create maps that display analyses of service area populations and demographics, facilities space management issues, spatial distribution of in-library use of materials, planned branch consolidations, and so on. The "seating sweeps" method allows researchers and librarians to collect in-library use data regarding where patrons are locating themselves within the library and what they are doing at those locations, such as sitting and reading, studying in a group, or socializing. This paper proposes a GIS as a tool to visually display in-library use data collected via "seating sweeps" of a library. By using a GIS to store, manage, and display the data, researchers and librarians can create visually appealing maps that show areas of heavy use and evidence of the use and value of the library for a community. Example maps are included to facilitate the reader's understanding of the possibilities afforded by using GISs in LIS research.

T he modern public library operates in a context of limited (and often continually reduced) funding where the librarians must justify the continued value of the library to funding and supervisory authorities. This is especially the case as more and more patrons access the library virtually, calling into question the relevance of the physical library. In this context, there is a great need for librarians and researchers to evaluate the use of library facility space to demonstrate that the physical library is still being used for important social and educational functions. Despite this need, no model of public library facility evaluation emphasizes the ways patrons use library facilities. The systematic collection of in-library use data must go beyond traditional circulation and reference transactions to include self-service activities, group study and collaboration, socializing, and more.

Geographic information systems (GISs) are beginning to become deployed in library and information science (LIS) research as a tool for graphically displaying data. An initial review of the literature has yielded studies where a GIS has been used in analyzing service area populations through U.S. Census data, ${ }^{1}$ sitting facility locations, ${ }^{2}$ managing facilities, including spatial distribution of in-library book use and occupancy of library study space, ${ }^{3}$ and planning branch consolidations. ${ }^{4}$ These uses of GIS are not mutually exclusive; studies have combined multiple uses of GISs. ${ }^{5}$ Also, GISs have been proposed as viable tools for producing visual representations of measurements of library facility use. ${ }^{6}$ These studies show the capabilities of a GIS for storing, managing, analyzing, and displaying in-library use data and the value of GISproduced maps for library facility evaluations, in-library use research, and library justification.

\section{Research purpose}

Observing and measuring the use of a library facility is a crucial step in the facility evaluation process. The library needs to understand how the facility is currently being used in order to justify the continued financial support necessary to maintain and operate it. Understanding how the facility is used can also help librarians identify hightraffic areas of the library that are ideal locations to market library services and materials. This understanding cannot be reached by analyzing circulation and reference transaction data alone; it must include in-library use measures that account for all ways patrons are using the facility. The purpose of this paper is to suggest a method by which to observe and record all uses of a library facility during a sampling period, the so-called "seating sweep" performed by Given and Leckie, and then to use a GIS to store, manage, and display the collected data on a map or series of maps that graphically depict library use. ${ }^{7}$

\section{Significance of facility evaluation}

Facility evaluation is a topic of vital importance in all fields, but this is especially true of a field such as public librarianship where funding is often a source of concern. ${ }^{8}$ In times of economic instability, libraries can benefit from the ability to identify uses of existing facilities and employ this information to justify the continued operation of the library facility. Also, knowing which areas of the library are more frequently used than others can help

Lauren H. Mandel (Imandel@fsu.edu) is a doctoral candidate at the Florida State University College of Communication \& Information, School of Library \& Information Studies, and is Research Coordinator at the Information Use Management \& Policy Institute. 
librarians determine where to place displays of library materials and advertisements of library services.

For a library to begin to evaluate patron use and how well the facility meets users' needs, there must be an understanding of what users need from the library facility. ${ }^{9}$ To determine those needs, it is vital that library staff observe the facility while it is being used. This observation can be applied to the facility evaluation plan to justify the continued operation of the facility to meet the needs of the library service population.

Understanding how people use the public library facility beyond traditional measures of circulation statistics and reference transactions can lead to new theories of library use, an area of significant research interest for LIS. Additionally, the importance of this work transcends LIS because it applies to other government-funded community service agencies as well. For example, recreation facilities and community centers could also benefit from a customer-use model that incorporates measures of the true use of those facilities.

\section{Literature review}

Although much has been written on the use of library facilities, little of the research includes studies of how patrons actually use existing public library facilities and whether facilities are designed to accommodate this use. ${ }^{10}$ Rather, much of the research in public library facility evaluation has focused on collection and equipment space needs, ${ }^{11}$ despite the user-oriented focus of public library accountability models. ${ }^{12}$ Recent research in library facility design is beginning to reflect this focus, ${ }^{13}$ but additional study would be useful to the field.

Use of GIS is on the rise in the modern technological world. A GIS is a computer-based tool for compiling, storing, analyzing, and displaying data graphically. ${ }^{14}$ Usually this data is geospatial in nature, but a GIS also can incorporate descriptive or statistic data to provide a richer picture than figures and tables can. Although GIS has been around for half a century, it has become increasingly more affordable, allowing libraries and similar institutions to consider using a GIS as a measurement and analysis tool.

GISs have started being used in LIS research as a tool for graphically displaying library data. One fruitful area has been the mapping of user demographics for facility planning purposes, ${ }^{15}$ including studies that mapped library closures. ${ }^{16}$ Mapping also can include in-library use data, ${ }_{1}^{17}$ in which case a GIS is used to overlay collected in-library use data on library floor plans. This can offer a richer picture of how a facility is being used than traditional charts and tables can provide.

\section{Using a GIS to display library service area population data}

Adkins and Sturges suggest libraries use a GIS-based library service area assessment as a method to evaluate their service areas and plan library services to meet the unique demographic demands of their communities. ${ }^{18}$ They discuss the methods of using GIS, including downloading U.S. Census TIGER (Topologically Integrated Geographic Encoding and Referencing) files, geocoding library locations, delineating service areas by multiple methods, and analyzing demographics. A key tenet of this approach is the concept that public libraries need to understand the needs of their patrons. This is a prevailing concept in the literature. ${ }^{19}$

Prieser and Wang, in reporting a method used to create a facilities master plan for the Public Library of Cincinnati and Hamilton County, Ohio, offer a convincing argument for combining GIS and building performance evaluation (BPE) methods to examine branch facility needs and offer individualized facilities recommendations. ${ }^{20}$ Like other LIS researchers, ${ }^{21}$ Preiser and Wang suggest a relationship between libraries and retail stores, noting the similar modern trends of destination libraries and destination bookstores. They also acknowledge the difficulty in completing an accurate library performance assessment due to the multitude of activities and functions of a library. Their method is a combination of a GIS-based service area and population analysis with a BPE that includes staff and user interviews and surveys, direct observation, and photography. The described multimethod approach offers a more complete picture of a library facility's performance than traditional circulation-based evaluations.

Further use of GISs in library facility planning can be seen from a study comparing proposed branches by demographic data that has been analyzed and presented through a GIS. Hertel and Sprague describe research that used a GIS to conduct geospatial analysis of U.S. Census data to depict the demographics of populations that would be served by two proposed branch libraries for a public library system in Idaho. ${ }^{22}$ A primary purpose of this research is to demonstrate the possible ways public libraries can use GIS to present visual and quantitative demographic analyses of service area populations. Hertel and Sprague identify that public libraries are challenged to determine which public they are serving and the needs of that population, writing that "libraries are beginning to add customer-based satisfaction as a critical component of resource allocation decisions" and need the help of a GIS to provide hard-data evidence in support of staff observations. ${ }^{23}$ This evidence could take the form of demographic data, as discussed by Hertel and Sprague, and also could incorporate in-library use data to present a fuller picture of a facility's use. 


\section{Using GIS to display in-library use data}

Xia conducted several studies in which he collected libraryuse data and mapped that data via a GIS. In one study designed to identify the importance of space management in academic libraries, Xia suggests applications of GISs in library space management, particularly his tool integrating library floor plans with feature data in a GIS. ${ }^{24} \mathrm{He}$ explains that a GIS can overcome the constraints of drafting and computer automated design tools, such as those in use at Chico Meriam Library at California State University and at the Michigan State University Main Library. For example, GISs are not limited to space visualization manipulation, but can incorporate user perceptions, behavior, and daily activities, all of which are important data to library space management considerations and in-library use research. Xia also reviews the use of GIS tools that incorporate hospital and casino floor plans, noting that library facilities are as equally complex as hospitals and casinos; this is a compelling argument that academic libraries should consider the use of a GIS as a space management tool.

In another study, Xia uses a GIS to visualize the spatial distribution of books in the library in an attempt to establish the relationship between the height of bookshelves and the in-library use of books. ${ }^{25}$ This study seeks to answer the question of how the location of books on shelves of different heights could influence user behavior (i.e., patrons may prefer to browse shelves at eye level rather than the top and bottom shelves). What is of interest here is Xia's use of a GIS to spatially represent the collected data. Xia remarks that a GIS "is suitable for assisting in the research of in-library book use where library floor layouts can be drawn into maps on multipledimensional views." ${ }^{26}$ In fact, Xia's graphics depict the use of books by bookshelf height in a visual manner that could not be achieved without the use of a GIS. Similarly, a GIS can be used to spatially represent the collected data in an in-library use study by overlaying the data onto a representation of the library floor plan.

In a third project, Xia measures study space use in academic libraries as a metric of user satisfaction with library services. ${ }^{27}$ He says that libraries need to evaluate space needs on case-by-case basis because every library is unique and serves a unique population. Therefore, to observe the occupancy of study areas in an academic library, Xia drew the library's study facilities (including furniture) in a GIS. He then observed patrons' use of the facilities and entered the observation data into the GIS to overlay on maps of the study areas. There are several advantages of using GIS in this way: Spatial databases can store continuing data sets, the system is powerful and flexible for manipulating and analyzing the spatial dataset, there are enhanced data visualization capabilities, and maps and data become interactive.

\section{Conclusions drawn from the literature}

A GIS is a tool gaining momentum in the world of LIS research. GISs have been used to conduct and display service area population assessments, ${ }^{28}$ propose facility locations, ${ }^{29}$ and plan for and measure branch consolidation impacts and benefits. ${ }^{30}$ GISs also have been used to graphically represent in-library use for managing facility space allocation, mapping in-library book use, and visualizing the occupancy of library study space. ${ }^{31}$ Additionally, GISs have been used in combination studies that examine library service areas and facility location proposals. ${ }^{32}$ These uses of GISs are only the beginning; a GIS can be used to map any type of data a library can collect, including all measures of in-library use. Additionally, GIS-based data analysis and display complements the focus in library-use research on gathering data to show a richer picture of a facility's use and the focus in library facility design literature on building libraries on the basis of community needs. ${ }^{33}$

\section{In-library use research that would benefit from spatial data displays}

Unobtrusive observational research offers a rich method for identifying and recording the use of a public library facility. A researcher could obtain a copy of a library's floor plan, predetermine sampling times during which to "sweep" the library, and conduct the sweeps by marking all patrons observed on the floor plan. ${ }^{34}$ This data then could be entered into a GIS database for spatial analysis and display.

Specific questions that could be addressed via such a method include the following:

- What are all the ways in which people are using the library facility?

- How many people are using traditional library resources, such as books and computers?

- How many people are using the facility for other reasons, such as relaxation, meeting friends, and so on?

- Do the ways in which patrons use the library vary by location within the facility (e.g., are the people using traditional library resources and the people using the library for other reasons using the same areas of the library or different areas)?

- Which area(s) of the library facility receive the highest level of use?

It is hoped that answers to these questions, in whole or in part, could begin to offer a picture of how a library facility is currently being used by library patrons.

To better view this picture, the data recorded from the observational research could be entered into a GIS to 


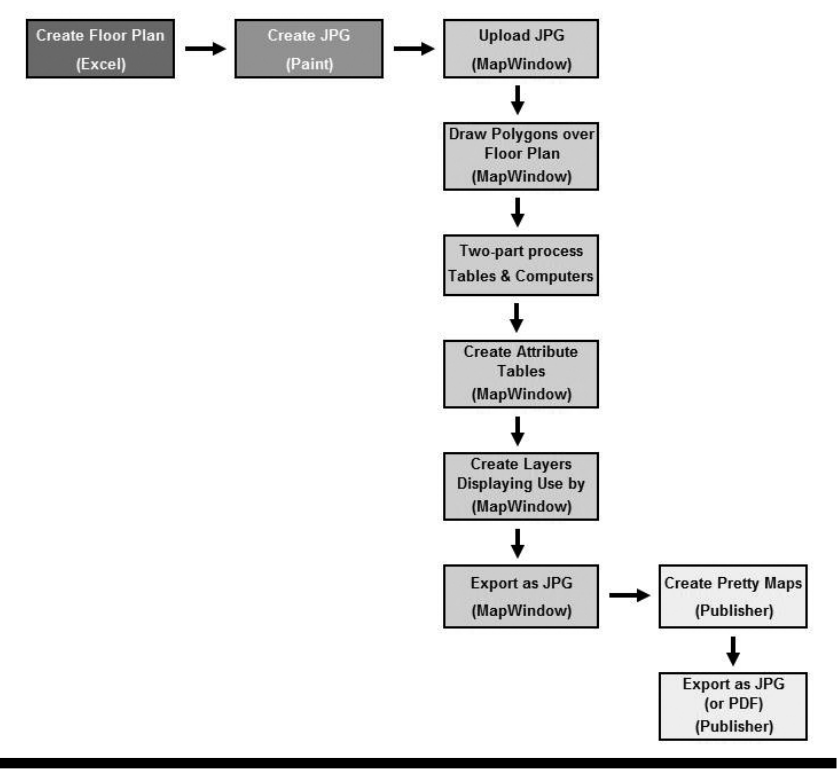

Figure 1. Process diagram for creating the sample maps

overlay onto the library floor plan in a similar manner as Xia's use of a GIS to display occupancy of library study space. ${ }^{35}$ This spatial representation of the data should facilitate greater understanding of the actual use of the library facility. Instead of a library presenting tables and graphs of library use, it would be able to produce illustrative maps that would help explain patterns of use to funding and supervising authorities. These maps would not require expensive proprietary GIS packages; the examples provided in this paper were created using the free, open-source MapWindow GIS package.

\section{Example using GIS to display in-library use data}

For this paper, I produced example maps on the basis of fictional in-library use data. These maps were created using MapWindow GIS software along with Microsoft Excel, Publisher, and Paint (see figure 1 for a diagram of this process). MapWindow is an open-source GIS package that is easy to learn and use, but its layout and graphic design features are limited compared to the more expensive and sophisticated proprietary GIS packages. ${ }^{36}$ MapWindow files are compatible with the proprietary packages, so they could be imported into other GIS packages for finishing. For this paper, however, the goal was to create simple maps that a novice could replicate. Therefore Publisher and Paint were used for finalizing the maps, instead of a sophisticated GIS package.

It was relatively easy to create the maps. First, I drew a sample floor plan of a fictional library computer lab in Excel and imported it into MapWindow as a JPEG file. I then overlaid polygons (shapes that represent area units

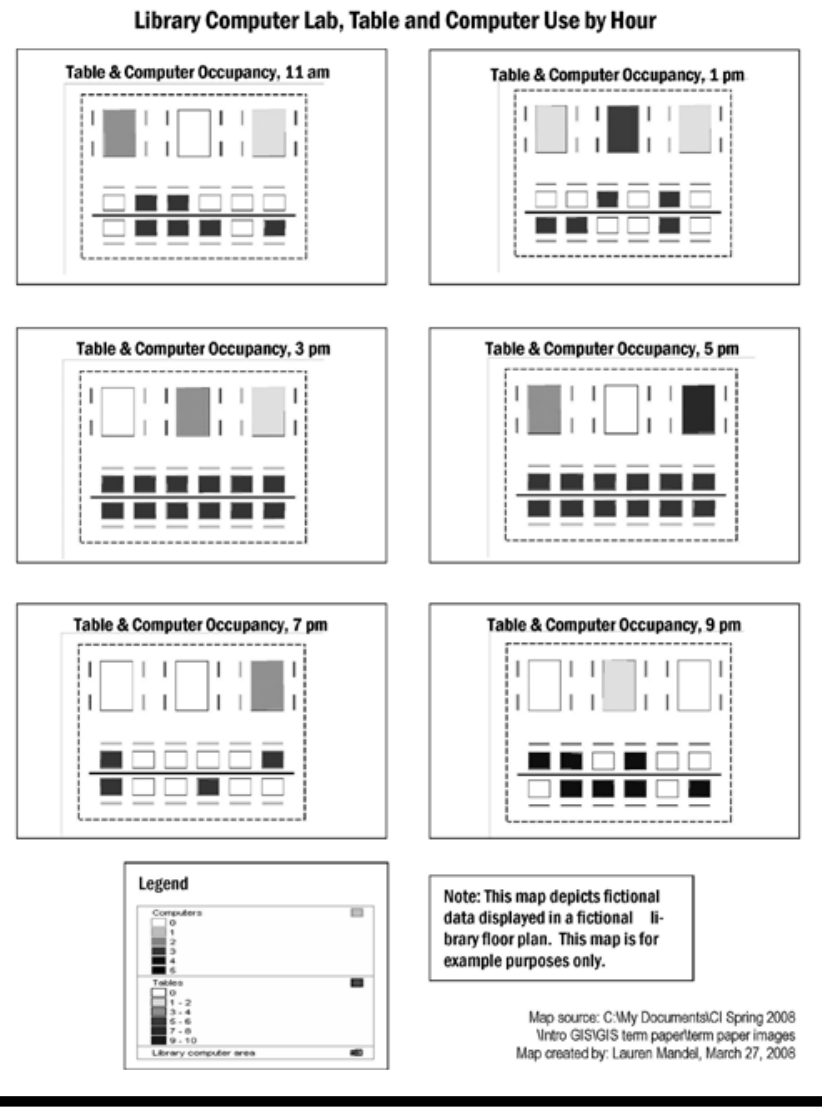

Figure 2. Example maps depicting use of tables and computers in a fictional library computer lab, by hour

such as chairs and tables) onto the floor plan and saved two shapefiles, one for tables and one for computers. A shapefile is a basic storage file used in most GIS packages. For each of those shapefiles I created an attribute table (basically, a linked spreadsheet) using fictitious data representing use of the tables and computers at 9 and 11 a.m. and 1,3,5, and 7 p.m. on a sample day. The field calculator generated a final column summing the total use of each table and computer for the fictitious sample day. I then created maps depicting the use of both tables and computers at each of the sample time periods (see figure 2 ) and for the total use (see figure 3 ).

\section{Benefits of GIS-created displays for library managers}

The maps presented here are not based on actual data, but are meant to demonstrate the capabilities of GISs for spatially representing the use of a library facility. This could be done on a grander scale using an entire library floor plan and data collected during a longer sample period (e.g., a full week). These maps can serve several purposes for 


\section{Library Computer Lab, Total Table and Computer Use for a Sample Day}



Figure 3. Example map depicting total use of tables and computers in a fictional library computer lab for a sample day

library managers, specifically regarding the marketing of library services and the justification of library funding.

Mapping data obtained from library "sweeps" can help identify the popularity of different areas of the library at different times of the day, different days of the week, or different times of the year. Once the library has identified the most popular areas, this information can be used to market library materials and services. For example, a highly populated area would be an ideal location over which to install ceiling-mounted signs that the library could use for marketing services and programs. Or the library could purchase a book display table similar to those used in bookstores and install it in the middle of a frequently populated area. The library could stock the table with seasonally relevant books and other materials (e.g., tax guidebooks in March and April) and track the circulation of these materials to determine the degree to which placement on the display table resulted in increased borrowing of those materials.
In addition to helping the library market its materials and services, mapping in-library use can provide visual evidence of the library's value. Public libraries often rely on reference and circulation transaction data, gate counts, and programming attendance statistics to justify their existence. These measures, although valuable and important, do not include many other ways that patrons use libraries, such as sitting and reading, studying, group work, and socializing. During "seating sweeps," the observers can record any and all uses they observe, including any that may not have been anticipated. All of these uses could then be mapped, providing a richer picture of how a public library is used and stronger justification of the library's value. These maps may be easier for funding and supervising authorities to understand than textual explanations or graphs and charts of statistical analyses.

\section{Conclusion}

From a review of the literature, it is clear that GISs are increasingly being used in LIS research as data-analysis and display tools. GISs are being used to analyze patron and materials data as well as studies combining combined multiple uses of GISs. Patron analysis has included service-area-population analysis and branch-consolidation planning. Analysis of library materials has been used for space management, visualizing the spatial distribution of in-library book use, and visual representation of facility-use measurements.

This paper has proposed collecting in-library use data according to Given and Leckie's "seating sweeps" method and visually displaying that data via a GIS. Examples of such visual displays were provided to facilitate the reader's understanding of the possibilities afforded by using a GIS in LIS research, as well as the scalable nature of the method. Librarians and library staff can produce maps similar to the examples in this paper with minimal GIS training and background. The literature review and example figures offered in this paper show the capabilities of GISs for analyzing and graphically presenting library-use data. GISs are tools that can facilitate library facility evaluations, in-library use research, and library valuation and justification.

\section{References}

1. Denice Adkins and Denyse K. Sturges, "Library Service Planning with GIS and Census Data," Public Libraries 43, no. 3 (2004): 165-70; Karen Hertel and Nancy Sprague, "GIS and Census Data: Tools for Library Planning," Library Hi Tech 25, no. 2 (2007): 246-59; Wolfgang F. E. Preiser and Xinhao Wang, "Assessing Library Performance with GIS and Building Evaluation Methods," New Library World 107, no. 1224-25 (2006): 193-217. 
2. Hertel and Sprague, "GIS and Census Data"; Preiser and Wang, "Assessing Library Performance."

3. Jingfeng Xia, "Library Space Management: A GIS Proposal," Library Hi Tech 22, no. 4 (2004): 375-82; Xia, "Using GIS to Measure In-Library Book-Use Behavior," Information Technology $\mathcal{E}$ Libraries 23, no. 4 (2004): 184-91; Xia, "Visualizing Occupancy of Library Study Space with GIS Maps," New Library World 106, no. 1212-13 (2005): 219-33.

4. Preiser and Wang, "Assessing Library Performance."

5. Hertel and Sprague, "GIS and Census Data"; Preiser and Wang, "Assessing Library Performance."

6. Preiser and Wang, "Assessing Library Performance"; Xia, "Library Space Management"; Xia, "Using GIS to Measure"; Xia, "Visualizing Occupancy."

7. Lisa M. Given and Gloria J. Leckie, "Sweeping' the Library: Mapping the Social Activity Space of the Public Library," Library E Information Science Research 25, no. 4 (2003): 365-85.

8. "Jackson Rejects Levy to Reopen Libraries," American Libraries 38, no. 7 (2007): 24-25; "May Levy Set for Jackson County Libraries Closing in April," American Libraries 38, no. 3 (2007): 14; "Tax Reform Has Florida Bracing for Major Budget Cuts," American Libraries 38, no. 8 (2007): 21.

9. Anne Morris and Elizabeth Barron, "User Consultation in Public Library Services," Library Management 19, no. 7 (1998): 404-15; Susan L. Silver and Lisa T. Nickel, Surveying User Activity as a Tool for Space Planning in an Academic Library (Tampa: Univ. of South Florida Library, 2002); James Simon and Kurt Schlichting, "The College Connection: Using Academic Support to Conduct Public Library Services," Public Libraries 42, no. 6 (2003): 375-78.

10. Given and Leckie, "Sweeping' the Library"; Christie M. Koontz, Dean K. Jue, and Keith Curry Lance, "Collecting Detailed In-Library Usage Data in the U.S. Public Libraries: The Methodology, the Results and the Impact," in Proceedings of the Third Northumbria International Conference on Performance Measurement in Libraries and Information Services (Newcastle, UK: University of Northumbria, 2001): 175-79; Koontz, Jue, and Lance, "Neighborhood-Based In-Library Use Performance Measures for Public Libraries: A Nationwide Study of MajorityMinority and Majority White/Low Income Markets Using Personal Digital Data Collectors," Library E Information Science Research 27, no. 1 (2005): 28-50.

11. Cheryl Bryan, Managing Facilities for Results: Optimizing Space for Services (Chicago: ALA, 2007); Anders C. Dahlgren, Public Library Space Needs: A Planning Outline (Madison, Wis.: Department of Public Instruction, 1988); William W. Sannwald and Robert S. Smith, eds., Checklist of Library Building Design Considerations (Chicago: ALA, 1988).

12. Brenda Dervin, "Useful Theory for Librarianship: Communication, Not Information," Drexel Library Quarterly 13, no. 3 (1977): 16-32; Morris and Barron, "User Consultation"; Preiser and Wang, "Assessing Library Performance"; Simon and Schlichting, "The College Connection"; Norman Walzer, Karen Stott, and Lori Sutton, "Changes in Public Library Services," Illinois Libraries 83, no. 1 (2001): 47-52.

13. Bradley Wade Bishop, "Use of Geographic Information Systems in Marketing and Facility Site Location: A Case Study of Douglas County (Colo.) Libraries," Public Libraries 47, no. 5: 65-69; David Jones, "People Places: Public Library Buildings for the New Millennium," Australasian Public Libraries $\mathcal{E}$ Information Services 14, no. 3 (2001): 81-89; Nolan Lushington,
Libraries Designed for Users: A 21st Century Guide (New York: Neal-Schuman, 2001); Shannon Mattern, "Form for Function: the Architecture for New Libraries," in The New Downtown Library: Designing with Communities (Minneapolis: Univ. of Minnesota Pr., 2007), 55-83.

14. United Nations, Department of Economic and Social Affairs, Statistics Division, Handbook on Geographical Information Systems and Mapping (New York: United Nations, 2000).

15. Adkins and Sturges, "Library Service Planning"; Bishop, "Use of Geographic Information Systems"; Hertel and Sprague, "GIS and Census Data"; Christie Koontz, "Using Geographic Information Systems for Estimating and Profiling Geographic Library Market Areas," in Geographic Information Systems and Libraries: Patrons, Maps, and Spatial Information, ed. Linda C. Smith and Mike Gluck (Urbana-Champaign: Univ. of Illinois Pr., 1996): 181-93; Preiser and Wang, "Assessing Library Performance."

16. Christie M. Koontz, Dean K. Jue, and Bradley Wade Bishop, "Public Library Facility Closure: An Investigation of Reasons for Closure and Effects on Geographic Market Areas," Library E Information Science Research 31, no. 2 (2009): 84-91.

17. Xia, "Library Space Management"; Xia, "Using GIS to Measure"; Xia, "Visualizing Occupancy."

18. Adkins and Sturges, "Library Service Planning."

19. Bishop, "Use of Geographic Information Systems"; Jones, "People Places"; Koontz, Jue, and Lance, "Collecting Detailed InLibrary Usage Data"; Koontz, Jue, and Lance, "NeighborhoodBased In-Library Use"; Morris and Barron, "User Consultation"; Simon and Schlichting, "The College Connection"; Walzer, Stott, and Sutton, "Changes in Public Library Services."

20. Preiser and Wang, "Assessing Library Performance."

21. Given and Leckie, "'Sweeping' the Library;" Christie M. Koontz, "Retail Interior Layout for Libraries," Marketing Library Services 19 , no. 1 (2005): 3-5.

22. Hertel and Sprague, "GIS and Census Data."

23. Ibid., 247.

24. Xia, "Library Space Management."

25. Xia, "Using GIS to Measure."

26. Ibid., 186.

27. Xia, "Visualizing Occupancy."

28. Adkins and Sturges, "Library Service Planning"; Hertel and Sprague, "GIS and Census Data"; Preiser and Wang, "Assessing Library Performance."

29. Hertel and Sprague, "GIS and Census Data"; Preiser and Wang, "Assessing Library Performance."

30. Koontz, Jue, and Bishop, "Public Library Facility Closure"; Preiser and Wang, "Assessing Library Performance."

31. Xia, "Library Space Management"; Xia, "Using GIS to Measure"; Xia, "Visualizing Occupancy."

32. Hertel and Sprague, "GIS and Census Data"; Preiser and Wang, "Assessing Library Performance."

33. Given and Leckie, "Sweeping' the Library"; Koontz, Jue, and Lance, "Collecting Detailed In-Library Usage Data"; Koontz, Jue, and Lance, "Neighborhood-Based In-Library Use"; Silver and Nickel, Surveying User Activity; Jones, "People Places"; Lushington, Libraries Designed for Users.

34. Given and Leckie, "Sweeping' the Library."

35. Xia, "Visualizing Occupancy."

36. For more information or to download MapWindow GIS, see http:/ / www.mapwindow.org/ 